\title{
Fetal polymorphisms at the $A B C B 1$-transporter gene locus are associated with susceptibility to non-syndromic oral cleft malformations
}

\author{
Ardeshir Omoumi ${ }^{1}$, Zihua Wang ${ }^{2,3}$, Vincent Yeow ${ }^{4}$, Yah-Huei Wu-Chou ${ }^{5,6}$, Philip K Chen ${ }^{6,7}$, Ingo Ruczinski ${ }^{8}$, \\ Joanne Cheng ${ }^{4}$, Felicia SH Cheah ${ }^{1}$, Caroline G Lee ${ }^{2,3,9}$, Terri H Beaty ${ }^{8}$ and Samuel S Chong ${ }^{\star, 1,10}$
}

ATP-binding cassette $(A B C)$ proteins in the placenta regulate fetal exposure to xenobiotics. We hypothesized that functional polymorphisms in $A B C$ genes influence risk for non-syndromic oral clefts (NSOC). Both family-based and case-control studies were undertaken to evaluate the association of nine potentially functional single-nucleotide polymorphisms within four $A B C$ genes with risk of NSOC. Peripheral blood DNA from a total of 150 NSOC case-parent trios from Singapore and Taiwan were genotyped, as was cord blood DNA from 189 normal Chinese neonates used as controls. In trios, significant association was observed between the $A B C B 1$ single-nucleotide polymorphisms and NSOC $(P<0.05)$. Only $A B C B 1$ rs 1128503 retained significant association after Bonferroni correction (odds ratio $(O R)=2.04 ; 95 \%$ confidence interval $(C I)=1.42-2.98$ ), while rs2032582 and rs 1045642 showed nominal significance. Association with rs 1128503 was replicated in a case-control analysis comparing NSOC probands with controls $(\mathrm{OR}=1.58 ; 95 \% \mathrm{Cl}=1.12-2.23)$. A comparison between the mothers of probands and controls showed no evidence of association, suggesting NSOC risk is determined by fetal and not maternal $A B C B 1$ genotype. The two studies produced a combined OR of $1.79(95 \% \mathrm{Cl}=1.38-2.30)$. The T-allele at rs 1128503 was associated with higher risk. This study thus provides evidence that potentially functional polymorphisms in fetal $A B C B 1$ modulate risk for NSOC, presumably through suboptimal exclusion of xenobiotics at the fetal-maternal interface. European Journal of Human Genetics (2013) 21, 1436-1441; doi:10.1038/ejhg.2013.25; published online 27 February 2013

Keywords: cleft palate; cleft lip; ATP-binding cassette transporters; single-nucleotide polymorphism; disease susceptibility; placenta

\section{INTRODUCTION}

The placenta represents the first fetal organ exposed to exogenous substances including drugs and potential fetotoxins present in maternal blood circulation. ${ }^{1}$ The placenta is formed by both fetal (chorionic plate and chorionic villi) and maternal (decidua basalis) tissues. The fetal placenta consists of syncytiotrophoblast and cytotrophoblast (or Langerhans) layers. Transporter proteins, such as ATP-binding cassette (ABC-transporter) are located at apical and basolateral surfaces of the syncytiotrophoblast and endothelial cells of fetal capillaries. ${ }^{2}$ These proteins are able to efflux environmental toxicants or drugs ingested by the mother into the maternal circulation. Therefore, the expression of transporter proteins within these structures is important in protecting the fetus from toxic xenobiotics. Expression and activity of these proteins in the placenta depend on gestational age and genetic polymorphisms. Functional single-nucleotide polymorphisms (SNPs) in $A B C$-transporter genes may influence expression and activity of these proteins in the placenta, leading to altered fetal exposure to xenobiotics, and subsequent increase in the risk of complex genetic disorders or birth defects.
Orofacial clefts (ie, cleft lip, cleft lip and palate, or cleft palate alone) are common craniofacial anomalies with an incidence of 1.0/1000-2.21/1000. ${ }^{3}$ In Asians, the prevalence rate of non-syndromic cleft lip with or without cleft palate has been reported as 1.19 per 1000 live births. ${ }^{4}$

Fetal lip development is completed at $\sim 5$ to 6 weeks of gestational age, and the palate will close $\sim 10$ weeks after gestation. Being a complex genetic disorder, orofacial malformations can be influenced by both genetic and environmental factors. It has been hypothesized that a cleft lip/palate forms when potential environmental risks, such as maternal cigarette smoking and, possibly, disruptions in the folate biosynthetic pathway ${ }^{5}$ interact with a genetically susceptible genotype, during the early stage of fetal development. This is a critical period when fusion of embryonic processes forming the upper lip and palate takes place. Studies have shown a positive association between formation of cleft lip/palate and maternal medication, ${ }^{6}$ maternal smoking, ${ }^{7}$ and alcohol use. ${ }^{8}$ Moreover, maternal infection, ${ }^{9}$ and folic acid deficiency ${ }^{10}$ may also contribute to orofacial malformations. Hence, we hypothesized that functional polymorphisms within $A B C$

${ }^{1}$ Department of Pediatrics, Yong Loo Lin School of Medicine, National University of Singapore, Singapore; ${ }^{2}$ Department of Biochemistry, Yong Loo Lin School of Medicine, National University of Singapore, Singapore; ${ }^{3}$ Division of Medical Sciences, Humphrey Oei Institute of Cancer Research, National Cancer Center Singapore, Singapore; ${ }^{4}$ Department of Plastic Surgery, KK Women's and Children's Hospital, Singapore; ${ }^{5}$ Department of Medical Research, Chang Gung Memorial Hospital, Linkou, Taiwan; ${ }^{6}$ Craniofacial Research Center, Chang Gung Memorial Hospital, Linkou, Taiwan; ${ }^{7}$ Departments of Plastic and Reconstructive Surgery, Chang Gung Memorial Hospital, Linkou, Taiwan; ${ }^{8}$ Department of Epidemiology, Johns Hopkins Bloomberg School of Public Health, Baltimore, MD, USA; ${ }^{9}$ Department of Cancer and Stem Cell Biology, Duke-NUS Graduate Medical School, National University of Singapore, Singapore; ${ }^{10}$ Department of Laboratory Medicine and University Children's Medical Institute, National University Hospital, Singapore

*Correspondence: Dr SS Chong, Department of Pediatrics, Yong Loo Lin School of Medicine, National University of Singapore, Singapore 119228, Singapore. Tel: + 656772 4152, Fax: + 656772 4100, E-mail: paecs@nus.edu.sg

Received 6 September 2012; accepted 17 January 2013; published online 27 February 2013 
genes expressed in placenta can potentially increase the risk for orofacial clefts through impairing the protective role of the placenta. Here, we examine the association between important functional polymorphisms in four major members of $\mathrm{ABC}$-transporter family, $A B C B 1 ; A B C C 1 ; A B C C 2 ; A B C G 2$, with non-syndromic orofacial clefts.

\section{MATERIALS AND METHODS}

\section{Study Design and Subjects}

This study used two formats of family-based and case-control studies. As the prevalence of non-syndromic oral clefts (NSOC) in Asians has been reported to be as low as 1.19 per 1000 live births, ${ }^{4}$ and trio designs are more powerful than case-control designs for rare diseases with prevalence of $0.1 \%,{ }^{11}$ we first performed the family-based analysis. The Quanto program ${ }^{12}$ was used to estimate the number of case-parent trios needed to detect genes exerting modest to strong levels of relative risks. Thus, a total of 150 case-parent trios were recruited through treatment centers in Singapore (KK Women's and Children's Hospital) and Taiwan (Chang Gung Memorial Hospital) with prior approval from the respective Institutional Review Boards (IRBs). They consisted of 128 Chinese, 10 Malay and 4 Indian trios, with an additional 8 trios of mixed or other ethnicity.

SNPs showing significant association with NSOC in the family-based study were validated in a case-control study. For the case-control analysis, 128 affected cases and 129 mothers of Chinese ethnicity from the trios were separately compared against unrelated controls consisting of 189 healthy Chinese neonates. Non-Chinese cases and mothers were excluded to minimize confounding due to population stratification and differences in genetic background. Ethnicity of the samples was confirmed via patient's medical files and hospital records.

\section{SNP Selection}

Nine potentially functional SNPs were selected from the four $A B C$-transporter genes to be evaluated for association with NSOC in our family-based study. SNPs showing significant association with NSOC were selected for case-control analysis. The selected SNPs have either been previously reported to be associated with drug response/function, or showed evidence of recent positive selection, or were reported to affect transcriptional regulation/splicing or the protein structure/function. Table 1 provides detailed information on the SNPs used in this study. Of note, we selected the three most commonly studied $A B C B 1$ SNPs (rs1128503, rs2032582, rs1045642), which are in strong linkage disequilibrium with high minor allele frequencies $(>10 \%)$ in Chinese, Malays and Indians. ${ }^{13,14}$

\section{Genotyping}

Using extracted DNA, SNP genotyping was performed using multiplex minisequencing and TaqMan SNP genotyping assays. In addition, DNA sequencing was employed to validate any borderline or ambiguous genotype data obtained from the multiplex minisequencing or TaqMan assays.

A single triplex PCR was designed to amplify fragments of $A B C B 1, A B C C 1$, and $A B C G 2$ containing the three SNPs, rs2032582, rs504348, and rs2231137, respectively. Triplex PCR amplifications were carried out in a reaction volume of $10 \mu \mathrm{l}$ containing PCR buffer (Qiagen, Valencia, CA, USA), $1.5 \mathrm{mM} \mathrm{MgCl}_{2}$, $0.5 \mathrm{ng}$ of genomic DNA, $200 \mu \mathrm{m}$ of each dNTP, $0.2 \mu \mathrm{M}$ of $A B C B 1,0.4 \mu \mathrm{M}$ of $A B C G 2,0.5 \mu \mathrm{M}$ of $A B C C 1$ primers, and one unit of HotStarTaq Polymerase (Qiagen) (PCR primer sequences are available in Supplementary Table S1). PCR conditions were as follows: initial cycle of $95^{\circ} \mathrm{C}$ for $15 \mathrm{~min}$, followed by 35 cycles of $94^{\circ} \mathrm{C}$ for $1 \mathrm{~min}, 65^{\circ} \mathrm{C}$ for $30 \mathrm{~s}$, and $72^{\circ} \mathrm{C}$ for $1 \mathrm{~min}$, and a final cycle of $72{ }^{\circ} \mathrm{C}$ for $5 \mathrm{~min}$. After verifying the PCR products on $1.5 \%$ agarose gel, PCR products were purified and subjected to multiplex minisequencing (minisequencing primer sequences are available in Supplementary Table S2). Genotyping of the remaining six SNPs was accomplished using the TaqMan SNP genotyping assay (Applied Biosystems, Foster City, CA, USA).

To validate borderline/ambiguous results obtained from TaqMan or minisequencing assays, genotyping was repeated by sequencing the DNA fragments containing the SNPs in the forward or reverse direction using the ABI PRISM BigDye V3.1 sequencing kit (Applied Biosystems). For $A B C B 1$ rs2032582 and $A B C G 2 \mathrm{rs} 2231137,0.16 \mu \mathrm{m}$ of the reverse PCR primer and $0.16 \mu \mathrm{M}$ of the forward PCR primer were used, respectively. For $A B C C 2$ rs2273697, the DNA fragment of interest was PCR-amplified in a reaction

Table 1 Selected potentially functional ABC SNPs.

\begin{tabular}{|c|c|c|c|c|c|}
\hline Gene & SNP & Reference SNP no. & Description & Association with function or disease phenotype & Reference numbers \\
\hline & e12/C1236T & rs1128503 & G412G & Increased exposure to irinotecan in cancer patients & 36 \\
\hline & & & & Altered $A B C B 1$ expression in $3 t 3$ isogenic fibro- & 33 \\
\hline & & & & blasts & 34 \\
\hline & & & & Lower ABCB1 expression & \\
\hline \multirow[t]{5}{*}{$A B C B 1$} & e21/G2677T & rs2032582 & A893S & Less placental trophoblast $A B C B 1$ expression in $T$ & 29 \\
\hline & e21/G2677A & & A893T & and $A$ carriers & \\
\hline & e26/C3435T & rs1045642 & $|1145|$ & Alteration in the rate of translation & 37 \\
\hline & & & & Lower ABCB1 expression & 34 \\
\hline & & & & Affects mRNA stability & 38 \\
\hline$A B C C 1$ & 5'FR/G-260C & rs504348 & $5^{\prime} \mathrm{UTR}$ & $\begin{array}{l}\text { Evidence of recent positive selection in European- } \\
\text { Americans }\end{array}$ & 39 \\
\hline \multirow[t]{6}{*}{$A B C C 2$} & e1/C-24T & rs717620 & $-24 \mathrm{C}>\mathrm{T}$ & Influenced ABCC2 mRNA expression in normal & $22,30,39$ \\
\hline & & & & kidney cortex and liver samples but not placenta & 39 \\
\hline & & & & Evidence of recent positive selection & \\
\hline & e10/G1249A & rs2273697 & V471I & Decreased ABCC2 mRNA levels in preterm placen- & 22 \\
\hline & & & & tas & 39 \\
\hline & & & & Evidence of recent positive selection & \\
\hline \multirow[t]{7}{*}{$A B C G 2$} & e5/C421A & rs2231142 & Q141K & Reduced ABCG2 activity & 40 \\
\hline & & & & Decreased ABCG2 protein level in placenta & 41 \\
\hline & & & & Evidence of recent positive selection & 39 \\
\hline & & & & Substrate recognition and/or transport of drugs & 42 \\
\hline & e2/G34A & rs2231137 & V12M & Reduced ABCG2 activity & 40 \\
\hline & & & & Substrate recognition and/or transport of drugs & 42 \\
\hline & 19/T-357C & rs2054576 & Intron & Alteration of pre-mRNA splicing & 43 \\
\hline
\end{tabular}


volume of $10 \mu \mathrm{l}$ containing $1 \mathrm{ng}$ of genomic DNA, $5 \mu \mathrm{l} 2 \times$ PCR master mix buffer (Qiagen), and $0.5 \mu \mathrm{M}$ of each primer (information of PCR primers are available in Supplementary Table S3). PCR conditions were as follows: initial cycle of $95^{\circ} \mathrm{C}$ for $15 \mathrm{~min}$, followed by 35 cycles of $95^{\circ} \mathrm{C}$ for $30 \mathrm{~s}, 62^{\circ} \mathrm{C}$ for $30 \mathrm{~s}$, and $72{ }^{\circ} \mathrm{C}$ for $30 \mathrm{~s}$, and a final cycle of $72^{\circ} \mathrm{C}$ for $5 \mathrm{~min}$. The PCR product was then sequenced using $0.16 \mu \mathrm{m}$ of the PCR reverse primer.

\section{Statistical Analysis}

Genotype data from the oral cleft patients and their biological parents were assessed for Mendelian consistency within each family, as well as for deviation from Hardy-Weinberg equilibrium (HWE) among the parents. Family-based analyses were performed using the transmission disequilibrium test (TDT) for biallelic SNPs, while the extended TDT (ETDT) developed by ${ }^{15}$ was used for tri-allelic SNP rs2032582. Alpha level was set to 0.05 .

Case-control comparisons were performed using the $\chi^{2}$-test, and odds ratios (ORs), as well as $95 \%$ confidence intervals (CIs) were calculated. An online software http://ihg.gsf.de/cgi-bin/hw/hwal.pldeveloped by T.M. Strom and T.F. Wienker, was employed to check for deviations from HWE and also to test for allelic and genotypic associations with NSOC under different genetic models, and alpha level was set to 0.05 .

To provide an overall estimate of the effect size of genetic risk found for NSOC in our family-based and case-control studies, we performed a combined analysis on the results of the two studies using the method described previously for integrated analysis on family-based and case-control studies. ${ }^{16}$

\section{RESULTS}

\section{Family-Based Study}

No deviation from HWE was observed for any of the SNPs examined in this study. TDT analysis of the nine selected SNPs in 150 trios revealed only $A B C B 1$ SNPs rs1128503, rs2032582, and rs1045642 were significantly associated with NSOC $(P<0.05)$, although among these only rs 1128503 retained its significance after Bonferroni correction for multiple testing (Table 2). For rs1128503 (C>T) and rs1045642 $(\mathrm{C}>\mathrm{T})$, further allelic analysis revealed a preferential transmission of their minor alleles (T) over the wild-type alleles (C) (Table 2). For the tri-allelic SNP rs2032582 (G>T, A), a $\chi^{2}$-statistic test $(\mathrm{df}=1)$ showed preferential transmission of the $\mathrm{T}$ and $\mathrm{A}$ alleles over the G-allele from heterozygous parents to the NSOC probands. After correction for multiple testing, however, only the T-allele (not the $\mathrm{G}$ or the A alleles) reached statistical significance $(P<0.05)$ (Table 3$)$.

\section{Case-Control Study}

We performed two sets of case-control comparisons to validate the family-based associations observed with SNPs rs1128503, rs2032582, and rs1045642. Firstly, the allele and genotype frequencies of the SNPs were compared between the Chinese NSOC probands $(n=128)$ and the healthy neonate controls $(n=189)$. The genotype distribution of the three SNPs were in HWE in the control group $(P>0.05)$. $\chi^{2}$-Analysis revealed significant allelic association between NSOC and $A B C B 1$ rs1128503, but not with rs2032582 or rs1045642 (Table 4A). Armitage's trend test produced a similar result (see Supplementary Table S4). Moreover, genotype-based analysis of rs1128503 revealed a higher risk for NSOC in carriers of at least one T-allele compared with the homozygous $\mathrm{CC}$ genotype $(\mathrm{OR}=2.32$; 95\% CI $=1.09-4.91 ; P=0.025)$. Conversely, a lower risk was observed for carriers of at least one C-allele compared with the homozygous TT genotype $(\mathrm{OR}=0.62 ; 95 \% \mathrm{CI}=0.40-0.97 ; P=0.038)$.

Secondly, the allele and genotype frequencies of the $A B C B 1$ SNPs were compared between Chinese mothers of NSOC probands $(n=129)$ and the neonate controls $(n=189)$, which disclosed no significant association between NSOC and any of the SNPs (Table 4B).

\section{Joint Analysis}

The joint analysis revealed evidence of homogeneity in ORs obtained from family-based and case-control studies for association of $A B C B 1$ rs1128503 with NSOC. Integrating the ORs from both studies, we

Table 2 Family-based TDT analysis.

\begin{tabular}{|c|c|c|c|c|c|c|c|c|c|}
\hline Gene & SNP & Reference SNP no. & $n 1$ & $n 2$ & $\begin{array}{c}\text { Transmitted/ } \\
\text { Not-transmitted }\end{array}$ & Observed & Corrected $^{a}$ & $O R$ & $95 \% \mathrm{Cl}$ \\
\hline \multirow[t]{3}{*}{$A B C B 1$} & e12/C1236T & rs1128503 & 150 & 108 & $\begin{array}{l}\text { T: } 92 / 45 \\
\text { C: } 45 / 92\end{array}$ & $5.1 \times 10^{-5}$ & $4.6 \times 10^{-4}$ & 2.04 & $1.45-2.99$ \\
\hline & $\begin{array}{l}\text { e21/G2677T } \\
\text { e21/G2677A }\end{array}$ & rs2032582 & 150 & 111 & $\begin{array}{l}\text { G: } 78 / 91 \\
\text { T: } 96 / 64 \\
\text { A: } 23 / 42\end{array}$ & 0.008 & 0.072 & $1.50^{\mathrm{b}}$ & $1.08-2.09$ \\
\hline & e26/C3435T & rs1045642 & 150 & 110 & $\begin{array}{l}\text { C: } 56 / 87 \\
\text { T: } 87 / 56\end{array}$ & 0.009 & 0.081 & 1.55 & $1.10-2.21$ \\
\hline$A B C C 1$ & 5'FR/G-260C & rs504348 & 150 & 7 & $\begin{array}{l}\text { G: } 03 / 04 \\
\text { C: } 04 / 03\end{array}$ & 0.705 & - & 1.33 & $0.23-9.10$ \\
\hline \multirow[t]{3}{*}{$A B C C 2$} & e1/C-24T & rs717620 & 150 & 76 & $\begin{array}{l}\text { C: } 41 / 50 \\
\text { T: } 50 / 41\end{array}$ & 0.345 & - & 1.24 & 0.811 .93 \\
\hline & e10/G1249A & rs2273697 & 150 & 53 & $\begin{array}{l}\text { G: } 34 / 22 \\
\text { A: } 22 / 34\end{array}$ & 0.107 & - & 1.55 & $0.88-2.77$ \\
\hline & $\mathrm{e} 5 / \mathrm{C} 421 \mathrm{~A}$ & rs2231142 & 150 & 110 & $\begin{array}{l}\text { C: } 70 / 62 \\
A: 62 / 70\end{array}$ & 0.486 & - & 1.13 & $0.79-1.62$ \\
\hline \multirow[t]{2}{*}{ ABCG2 } & e2/G34A & rs2231137 & 150 & 105 & $\begin{array}{l}\text { G: } 54 / 71 \\
\text { A: } 71 / 54\end{array}$ & 0.127 & - & 1.32 & $0.91-1.91$ \\
\hline & 19/T-357C & rs2054576 & 150 & 91 & $\begin{array}{l}\text { T: } 59 / 51 \\
\text { C: } 51 / 59\end{array}$ & 0.445 & - & 1.16 & $0.78-1.72$ \\
\hline
\end{tabular}

Abbreviations: $\mathrm{Cl}$, confidence Interval; $\mathrm{OR}$, odds ratio; $\mathrm{n} 1$, number of family samples which were successfully genotyped; $\mathrm{n} 2$, number families with at least one heterozygote parent.

$P$-value of $<0.01$ are highlighted in bold.

after adjustment for multiple comparisons $(N=9)$.

bofter adjustment 
obtained a combined $\mathrm{OR}=1.79 \quad(95 \% \quad \mathrm{CI}=1.38-2.30 ; \quad P$-value $<0.0001)$ for association between rs1128503 and NSOC.

\section{DISCUSSION}

During fetal development, modulation of maternal exposure to environmental factors, as well as modulation of fetal exposure to potentially toxic xenobiotics digested by the mother is vital. The ABCtransporter proteins $\mathrm{ABCB} 1, \mathrm{ABCC} 1, \mathrm{ABCC} 2$, and $\mathrm{ABCG} 2$ are known to be expressed in maternal barrier organs (intestine, kidney, liver, lung) and the fetal barrier organ (placenta). ABCB1 is highly expressed in human placenta during early gestation, ${ }^{17-19}$ while ABCG2 is expressed more in mid gestation. ${ }^{20}$ During late gestation, $\mathrm{ABCC}^{21}$ and $\mathrm{ABCC}^{22}$ show the highest placental expression. Therefore, we can speculate that ABCB1 is vital in protecting the early fetus from xenobiotics insult, ${ }^{23,24}$ such as maternal pharmacotherapy and even fetal waste products, while ABCC1, $\mathrm{ABCC} 2$, and $\mathrm{ABCG} 2$ can provide better protection to the mature

Table 3 Transmission of $A B C B 1$ rs2032582 alleles.

\begin{tabular}{lccc}
\hline Allele & $A$ & $G$ & $T$ \\
\hline Number of times transmitted (T) & 23 & 78 & 96 \\
Expected value for Ta & 32.5 & 84.5 & 80 \\
Number of times not-transmitted (NT) & 42 & 91 & 64 \\
Expected value for NTa & 32.5 & 84.5 & 80 \\
Observed P-value & 0.019 & 0.317 & 0.011 \\
Bonferroni corrected $P$-value & 0.057 & 0.951 & 0.033 \\
\hline
\end{tabular}

${ }^{\mathrm{a}}$ Expected values were calculated as $(T+N T) / 2$. $P$-value of $<0.05$ is indicated in bold fetus. Given lip and palate formation is completed by the first trimester of pregnancy, the role of placental ABCB1 appears to be most crucial. This may explain why we observed association of oral clefting with only $A B C B 1$, and not $A B C C 1, A B C C 2$, or $A B C G 2$, SNPs $(P>0.05)$.

The $A B C B 1$ gene has been associated with cleft palate in the mouse model. Lankas et a ${ }^{25}$ examined homozygote $(-/-)$ and heterozygote $(+/-)$ ABCB1 knockout mice exposed to a teratogenic agent (avermectin), and found homozygote $-/$ - fetuses were $100 \%$ susceptible to cleft palate when exposed. In contrast, heterozygotes $(+/-)$ were less sensitive $(30 \%$ of fetuses had cleft palate) and homozygotes $+/+$ fetuses were insensitive at the tested doses. Hence, ABCB1, which is present at the maternal-fetal interface, may have an important role in regulating the traffic of teratogenic agents across the placenta, and the degree of fetal exposure to chemicals could be dependent on the expression of placental ABCB1. In this regard, homozygous $A B C B 1$ knockout mice showed many fold higher transplacental transport of ABCB1 substrates such as digoxin, saquinavir, and paclitaxel compared with wild-type mice. ${ }^{26}$

It is possible fetal $\mathrm{ABCB} 1$ has a crucial role during the formation of lips and palate by minimizing fetal exposure to potentially fetotoxic substances. Fetal $A B C B 1$ polymorphisms could increase the risk of NSOC by altering $A B C B 1$ expression or activity. Interestingly, the mean expression of $\mathrm{ABCB} 1$ has been found to be two times higher in the early (13-14 week) compared with the late (full-term) gestation human placenta, which is mostly fetal in origin. ${ }^{17-19}$

We observed significant association with ABCB1 SNPs rs1128503, rs2032582, and rs1045642, although only rs1128503 remained significant after Bonferroni correction. It should be noted, however, that SNPs, rs1128503, rs2032582, and rs1045642, are not independent but are in strong linkage disequilibrium, ${ }^{14}$ therefore application of

Table 4 Case-control $\chi^{2}$-analysis.

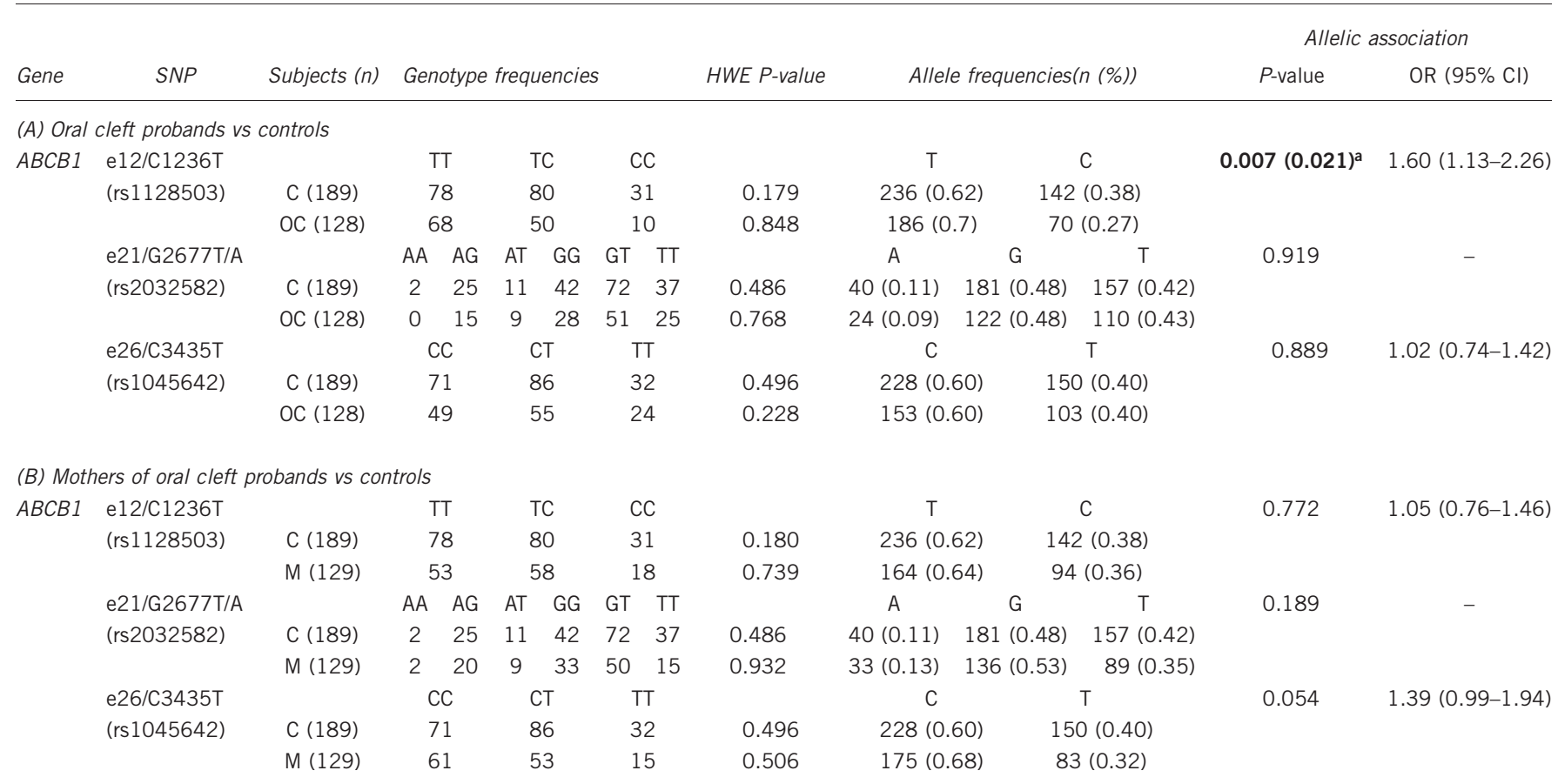

Abbreviations: C, control; $\mathrm{Cl}$, confidence interval; HWE, Hardy-Weinberg equilibrium; M, mothers; OC, oral clefts; OR, odds ratio.

$P$-value of $<0.05$ highlighted in bold.

aBonferroni corrected. 
Bonferroni correction would result in an overly conservative correction. In the case-control study between Chinese NSOC probands and ethnic-matched controls, $A B C B 1$ rs1128503 was confirmed to be significantly associated with NSOC by both allelic and genotypic analyses, despite our modest sample size and limited power $(<60 \%)$ in case-control analysis. ${ }^{11}$ There was a high risk for developing NSOC in carriers of at least one T-allele of rs 1128503 compared with those with the CC genotype. This observation is also consistent with the results of our family-based study, which showed preferential transmission of the T-allele to NSOC probands compared with the C-allele. A joint analysis of these data from the family and casecontrol studies for $A B C B 1$ rs1128503 revealed a high effect size for the role of this polymorphism in susceptibility to NSOC. In another comparison between Chinese mothers of NSOC probands and ethnicmatched healthy controls, no significant association was observed between the $A B C B 1$ SNPs and NSOC, suggesting the status of $A B C B 1$ polymorphism in fetus, and not in mother, is the determinant for conferring risk for NSOC.

In our family-based study, SNP allele analysis also revealed rs2032582 T-allele had significantly higher transmission to NSOC probands compared with the A- and G- alleles. In addition, rs 1045642 T-allele was observed to have higher transmission to affected offspring compared with the $\mathrm{C}$-allele. These findings are consistent with previous studies reporting the rs2032582 and rs1045642 T-alleles were associated with lower expression of $\mathrm{ABCB} 1$ in term placentas. ${ }^{27-}$ ${ }^{29}$ In contrast, other studies have reported higher levels of ABCB1 mRNA expression in kidney ${ }^{30}$ and heart ${ }^{31}$ tissues of carriers of rs2032582 T- and A-alleles compared with G-allele carriers. However, regulation of $\mathrm{ABCB} 1$ expression may differ significantly from tissue to tissue. Moreover, linkage studies in Chinese, Malays, and Indians have disclosed that the T-allele of SNPs rs1128503, rs2032582, and rs1045642 are in strong linkage disequilibrium. ${ }^{14}$ Hence, the observed preferential transmission of the T-alleles of these SNPs could be due to a haplotype effect that needs to be further evaluated.

Although rs1128503 is a silent/synonymous SNP, a potentially functional role for this polymorphism has been observed by others. ${ }^{32}$ It has been observed in 3T3 isogenic fibroblasts, mutation at e12/1236 (rs1128503) can significantly alter ABCB1 expression, regardless of additional mutations at positions e21/2677 (rs2032582) and e26/3435 (rs1045642). ${ }^{33}$ Another study has reported effects of $A B C B 1$ polymorphisms at e21/2677 and e26/3435 on expression of ABCB1 in term placentas. ${ }^{27}$ Our observation of a higher risk for NSOC in carriers of rs1128503 T-allele is also in accord with a previous report that the $\mathrm{T}$-variant significantly alters $\mathrm{ABCB} 1$ expression in breast tumors. ${ }^{34}$ We speculate that fetal genotypes at $A B C B 1$ carrying the rs1128503 T-allele are more vulnerable to NSOC, especially under situations of maternal exposure to non-genetic risk factors for NSOC such as smoking or pharmacotherapy. It is also possible rs1128503 is not a causal polymorphism but is merely in strong linkage disequilibrium with an unobserved causal SNP.

ABCB1 expression has been reported to be affected by both genetic polymorphisms $\mathrm{s}^{27}$ and environmental factors, such as diet and drugs. ${ }^{32}$ However, one study reported no significant difference in placental $\mathrm{ABCB} 1$ activity or expression between smokers and non-smokers. ${ }^{24}$ In our current study, the genetic marker was considered as the main determinant for expression of ABCB1 in the placenta, and the effect of non-genetic factors such as maternal smoking and medication in pregnancy was assumed to be minimal. However, it is possible even in the presence of wild-type placental $A B C B 1$ genotype, fetuses exposed to potentially toxic xenobiotics are also at higher risk for NSOC. This is because the concurrent exposure to multiple substrates of $\mathrm{ABCB} 1$, or an $\mathrm{ABCB} 1$ inhibitor, may impair placental ABCB1 activity. ${ }^{35}$

In conclusion, findings from our family-based and case-control studies of nine potentially functional polymorphisms within $A B C B 1$, $A B C C 1, A B C C 2$, and $A B C G 2$ provide strong support for the role of $A B C B 1$ polymorphisms in conferring risk for NSOC. Our results also suggest pharmacogenetic testing of $A B C$-transporter genes should also involve fetal DNA testing to estimate the risk of maternal medications on fetal development.

\section{CONFLICT OF INTEREST}

The authors declare no conflict of interest.

\section{ACKNOWLEDGEMENTS}

We are grateful to all participants who donated samples for this multi-center collaborative research on oral clefts. This research was supported by grants from the United States National Institute of Dental and Craniofacial Research (No. R21-DE-013707 and R01-DE-014581) and the Singapore National Healthcare Group (No. NHG BRG/01004). Dr Omoumi was supported by an International Graduate Scholarship from A*STAR (Agency for Science, Technology and Research), Singapore.

1 Gupta RC, Sastry BV: Toxicology of the Placenta, in General and Applied Toxicology, (eds Ballantyne B, Marrs T, Syversen T) 1233-1263 (Grove's Dictionaries, Inc: New York, 2000)

2 St-Pierre MV, Serrano MA, Macias RI et al: Expression of members of the multidrug resistance protein family in human term placenta. Am J Physiol Regul Integr Comp Physiol 2000; 279: R1495-R1503.

3 Derijcke A, Eerens A, Carels C: The incidence of oral clefts: a review. Br J Oral Maxillofac Surg 1996; 34: 488-494.

4 Cooper Me, Ratay JS, Marazita ML: Asian oral-facial cleft birth prevalence. Cleft Palate Craniofac J 2006; 43: 580-589.

5 Jugessur A, Murray JC: Orofacial clefting: recent insights into a complex trait. Curr Opin Genet Dev 2005; 15: 270-278.

6 Arpino C, Brescianini S, Robert E et al: Teratogenic effects of antiepileptic drugs: use of an International Database on Malformations and Drug Exposure (MADRE). Epilepsia 2000; 41: 1436-1443.

7 Little J, Cardy A, Munger RG: Tobacco smoking and oral clefts: a meta-analysis. Bull World Health Organ 2004; 82: 213-218.

8 Lorente C, Cordier S, Goujard J et al: Tobacco and alcohol use during pregnancy and risk of oral clefts. Occupational Exposure and Congenital Malformation Working Group. Am J Public Health 2000; 90: 415-419.

9 Natsume N, Kawai T, Ogi N, Yoshida W: Maternal risk factors in cleft lip and palate: case control study. Br J Oral Maxillofac Surg 2000; 38: 23-25.

10 Hernandez-Diaz S, Werler MM, Walker AM, Mitchell AA: Folic acid antagonists during pregnancy and the risk of birth defects. N Engl J Med 2000; 343: 1608-1614.

11 Laird NM, Lange C: Family-based designs in the age of large-scale gene-association studies. Nat Rev Genet 2006; 7: 385-394.

12 Gauderman WJ: Sample size requirements for matched case-control studies of geneenvironment interaction. Stat Med 2002; 21: 35-50.

$13 \mathrm{Kim} \mathrm{RB}$, Leake BF, Choo EF et al: Identification of functionally variant MDR1 alleles among European Americans and African Americans. Clin Pharmacol Ther 2001; 70: 189-199.

14 Tang K, Ngoi SM, Gwee PC et al: Distinct haplotype profiles and strong linkage disequilibrium at the MDR1 multidrug transporter gene locus in three ethnic Asian populations. Pharmacogenetics 2002; 12: 437-450.

15 Sham PC, Curtis D: An extended transmission/disequilibrium test (TDT) for multi-allele marker loci. Ann Hum Genet 1995; 59: 323-336.

16 Kazeem GR, Farrall M: Integrating case-control and TDT studies. Ann Hum Genet 2005; 69: 329-335.

17 Gil S, Saura R, Forestier F, Farinotti R: P-glycoprotein expression of the human placenta during pregnancy. Placenta 2005; 26: 268-270

18 Mathias AA, Hitti J, Unadkat JD: P-glycoprotein and breast cancer resistance protein expression in human placentae of various gestational ages. Am J Physiol Regul Integr Comp Physiol 2005; 289: R963-R969.

19 Sun M, Kingdom J, Baczyk D, Lye SJ, Matthews SG, Gibb W: Expression of the multidrug resistance P-glycoprotein, (ABCB1 glycoprotein) in the human placenta decreases with advancing gestation. Placenta 2006; 27: 602-609.

20 Mao Q: BCRP/ABCG2 in the placenta: expression, function and regulation. Pharm Res 2008; 25: 1244-1255.

21 Pascolo L, Fernetti C, Pirulli D, Crovella S, Amoroso A, Tiribelli C: Effects of maturation on RNA transcription and protein expression of four MRP genes in human placenta and in BeWo cells. Biochem Biophys Res Commun 2003; 303: 259-265. 
22 Meyer zu Schwabedissen HE, Jedlitschky G, Gratz M et al: Variable expression of MRP2 (ABCC2) in human placenta: influence of gestational age and cellular differentiation. Drug Metab Dispos 2005; 33: 896-904.

23 Ceckova-Novotna M, Pavek P, Staud F: P-glycoprotein in the placenta: expression, localization, regulation and function. Reprod Toxicol 2006; 22: 400-410.

24 Kolwankar D, Glover DD, Ware JA, Tracy TS: Expression and function of ABCB1 and ABCG2 in human placental tissue. Drug Metab Dispos 2005; 33: 524-529.

25 Lankas GR, Wise LD, Cartwright ME, Pippert T, Umbenhauer DR: Placental P-glycoprotein deficiency enhances susceptibility to chemically induced birth defects in mice. Reprod Toxicol 1998; 12: 457-463.

26 Smit JW, Huisman MT, van Tellingen O, Wiltshire HR, Schinkel AH: Absence or pharmacological blocking of placental P-glycoprotein profoundly increases fetal drug exposure. J Clin Invest 1999; 104: 1441-1447.

27 Hitzl M, Schaeffeler E, Hocher B et al: Variable expression of P-glycoprotein in the human placenta and its association with mutations of the multidrug resistance 1 gene (MDR1, ABCB1). Pharmacogenetics 2004; 14: 309-318.

28 Sherif A-R, Tatiana N, Gary DVH, Mahmoud A: Effect of the G2677A/T polymorphism in the multidrug resistance 1 gene (MDR1, ABCB1) on P-glycoprotein (P-gp) expression in human placenta. Am J Obs Gyn 2007; 197: S172.

29 Tanabe M, leiri I, Nagata $\mathrm{N}$ et al: Expression of P-glycoprotein in human placenta: relation to genetic polymorphism of the multidrug resistance (MDR)-1 gene. $J$ Pharmacol Exp Ther 2001; 297: 1137-1143.

30 Haenisch S, Zimmermann U, Dazert E et al: Influence of polymorphisms of ABCB1 and $\mathrm{ABCC} 2$ on mRNA and protein expression in normal and cancerous kidney cortex. Pharmacogenomics J 2007; 7: 56-65.

31 Meissner K, Jedlitschky G, Meyer zu Schwabedissen $\mathrm{H}$ et al: Modulation of multidrug resistance P-glycoprotein 1 (ABCB1) expression in human heart by hereditary polymorphisms. Pharmacogenetics 2004; 14: 381-385.

32 Jeong H, Herskowitz I, Kroetz DL, Rine J: Function-altering SNPs in the human multidrug transporter gene $A B C B 1$ identified using a Saccharomyces-based assay. PLoS Genet 2007; 3: e39.
33 Aird RE, Thomson M, Macpherson JS, Thurston DE, Jodrell DI, Guichard SM: $A B C B 1$ genetic polymorphism influences the pharmacology of the new pyrrolobenzodiazepine derivative SJG-136. Pharmacogenomics J 2008; 8: 289-296.

34 Vaclavikova R, Nordgard SH, Alnaes GI et al: Single nucleotide polymorphisms in the multidrug resistance gene 1 ( $A B C B 1$ ): effects on its expression and clinicopathological characteristics in breast cancer patients. Pharmacogenet Genomics 2008; 18 : 263-273.

35 Abu-Qare Aw, Elmasry E, Abou-Donia MB: A role for P-glycoprotein in environmental toxicology. J Toxicol Environ Health B Crit Rev 2003; 6: 279-288.

36 Mathijssen RH, Marsh S, Karlsson MO et al: Irinotecan pathway genotype analysis to predict pharmacokinetics. Clin Cancer Res 2003; 9: 3246-3253.

37 Kimchi-Sarfaty C, Oh JM, Kim IW et al: A "silent" polymorphism in the MDR1 gene changes substrate specificity. Science 2007; 315: 525-528.

38 Wang D, Johnson AD, Papp AC, Kroetz DL, Sadee W: Multidrug resistance polypeptide 1 (MDR1, ABCB1) variant $3435 \mathrm{C}>\mathrm{T}$ affects mRNA stability. Pharmacogenet Genomics 2005; 15: 693-704.

39 Wang Z, Wang J, Tantoso E et al: Signatures of recent positive selection at the ATPbinding cassette drug transporter superfamily gene loci. Hum Mol Genet 2007a; 16: 1367-1380.

40 Mizuarai S, Aozasa N, Kotani H: Single nucleotide polymorphisms result in impaired membrane localization and reduced ATPase activity in multidrug transporter ABCG2. Int J Cancer 2004; 109: 238-246.

41 Kobayashi D, leiri I, Hirota $T$ et al: Functional assessment of ABCG2 (BCRP) gene polymorphisms to protein expression in human placenta. Drug Metab Dispos 2005; 33: 94-101.

42 Tamura A, Wakabayashi K, Onishi Y et al: Re-evaluation and functional classification of non-synonymous single nucleotide polymorphisms of the human ATP-binding cassette transporter ABCG2. Cancer Sci 2007; 98: 231-239.

43 Yeo GW, Van Nostrand EL, Liang TY: Discovery and analysis of evolutionarily conserved intronic splicing regulatory elements. PLoS Genet 2007; 3: e85.

Supplementary Information accompanies this paper on European Journal of Human Genetics website (http://www.nature.com/ejhg) 